\title{
Effectiveness Of Topical Application Of Chlorhexidine And Prevailing Practices On Episiotomy Wound Among Postnatal Mothers
}

\author{
Rincy Michael* ${ }^{1}$, Soney N Toppo ${ }^{2}$, Varsha Hariharan ${ }^{2}$ \\ ${ }^{1}$ Clinical Instructor, Aurvindo College of Nursing, Bhopal \\ ${ }^{2}$ Associate Professor, Choithram College of Nursing, Manik Bagh Road,Indore
}

\section{Abstract}

Puerperium is a period when the mother experiences intense physical and emotional stress due to exhaustion, anxiety and excitement. Each mother has to adjust to physical changes in her own body due to involution and lactation as well as cope up with the new demands on her time and emotions made by the new born baby. Episiotomy, despite evidences that it is an unnecessary intervention, is one of the most common surgical procedures performed during the second stage of labour, especially in primigravida woman. Thus, a randomized controlled trial to assess the effectiveness of topical application of chlorhexidine and prevailing practices on episiotomy wound among postnatal mothers at selected hospital of Indore was undertaken. True experimental approach with pre test post test research design was adopted. Simple random sampling was taken to select 40 postnatal mothers with episiotomy wound and three days postpartum hospital stay in Choithram Hospital \& Research Centre, Indore as per the inclusion criteria. Data was collected with help of questionnaire for socio demographic data and obstetrical data and the wound healing was assessed by REEDA wound healing assessment scale. Samples in the experimental group were applied with chlorhexidine on episiotomy wound and the samples in the control group received routine care with betadine or nadoxin. Post assessment score was taken on third day (evening) by REEDA wound assessment scale. Finding of the study related to effectiveness of chlorhexidine among postnatal mothers in experimental group revealed that there was a significant difference in the healing of episiotomy wound by the application of chlorhexidine among postnatal mothers in experimental group at t $19=11.40$ at the level of $\mathrm{p}<0.001$. Hence it was inferred that topical application of chlorhexidine on episiotomy wound promotes wound healing.

Key Words: Chlorhexidine, Effectiveness, Episiotomy wound, Postnatal mothers, Prevailing practices.

\section{INTRODUCTION}

$\mathrm{W}$ hen the extraordinary changes in physiology that occur throughout pregnancy is considered, it should come as no surprise that the period of physiological adjustment and recovery following the end of pregnancy is both complex and closely related to the overall health status of the individual. The intricate relationships between physiological, psychological and sociological factors are encompassed in the remit of postnatal care. (Fraser MD, 2000)[1]

The decision to perform an episiotomy appears to be influenced by the type of obstetrical provider. Specifically, private practitioners and faculty providers are more likely than midwives to use this procedure (four-fold and two-fold higher, respectively) Robinson JN (2000) [2]

Maternal position, parity, and use of epidural anesthesia also appear to play a role in the decision to perform episiotomy. An upright or lateral maternal childbirth position is associated with fewer episiotomies than the supine or lithotomy positions, while epidural anesthesia and primiparity may increase the incidence. Episiotomy is more common with operative than spontaneous vaginal deliveries (71 versus 33 percent) Gupta JK (2012)[3]

During the last three decades the incidence of episiotomy increased worldwide because of associated advantages (Cunningham, 2001)[4]. The arguments in favour of episiotomy were that it creates a clean and straight incision which is easier to repair compared to a perineal tear; that an incised wound facilities healing; that a surgical cut prevents lacerations; that the incision facilitates labour by shortening the second stage; and finally, that it lowers incidence of neonatal brain injury by reducing pressure

\section{Address for correspondence*}

Rincy Michael,

Clinical Instructor, Aurvindo College of Nursing, Bhopal,

Email ID: rincy.michael@rediffmail..com,

Mobile No: 09981589301 on fetal head. Though several of these have been refuted by later research evidence, episiotomy still dominates normal labour room procedures of the second stage.

Patricia Janet A (2007) [5] stated that, perineal hygiene helps the mother in cleaning of her perineum after each voiding and evacuation. Clean the perineal area from the front to back to avoid infection. Clean with warm water or clean water or with antiseptic solution. Apply perineal pad from front to back. Instruct mother to wear perineal pads loosely and to lie in Sim's position (sidelying position). Episiotomy suture is cleaned with antiseptic solution and observed for any redness, edema, ecchymosis; discharge and approximation of wound etc. apply ice or cold to decrease edema and reduction in pain due to anaesthetic effect. Apply dry or moist heat to the episiotomy for comfort and healing.

Episiotomies are performed on over $90 \%$ of first-time mothers delivering in major United States Hospitals. In Netherland, by way of contrast they are performed in only $8 \%$ of births.

Therefore the researcher selected "An experimental study to assess the effectiveness of topical application of chlorhexidine and prevailing practices on episiotomy wound among postnatal mothers at selected hospital of Indore in the year 2012-2013".

\section{Objectives}

1) To determine the level of healing of episiotomy wound among postnatal mothers in control and experimental group.

2) To compare the episiotomy wound healing status of postnatal mothers among control group and experimental group.

3) To evaluate the effectiveness of chlorhexidine of postnatal mothers in experimental group.

\section{MATERIALSAND METHODS}

Research Design True experimental research design.

Population Postnatal mothers having episiotomy 
wound and three dayspostpartum hospital stay

Sampling technique The method of sampling employed was simple random sampling

Samplesize The sample size was 40 postnatal mothers, 20 in each group

Setting Choithram Hospital \& Research

Centre, Indore

Tool The tool for collection of data for this study consisted of two sections:

$\varnothing \quad$ Section A(I): Socio demographic data

$\varnothing \quad$ Section A(II): Obstetrical data

$\varnothing \quad$ Section B: REEDA wound healing assessment scale

Validity The prepared tool along with the statement, objectives, hypotheses, operational definitions and criteria checklist were given to 2 obstetricans, 4 nursing personnel and 1 researcher statistician

Reliability

Standarised REEDA wound healing assessment scale was used.

Pilotstudy The pilot study was conducted in Choithram Hospital \& Research Centre, Indore from 19th December 2012 to 27th December 2012.

Data for the pilot study were collected from 6 postnatal mothers who fulfilled the inclusion criteria.

The analysis of the pilot study revealed that the objectives of the study could be fulfilled. Based on this information, researcher proceeded with the actual data collection for the main study.

Data Collection Procedure

Data collection period was from 4th January 2013 to 4th February 2013. The researcher collected data of 40 postnatal mothers who fulfilled the inclusion criteria. Ethical consideration was fulfilled by taking written permission from the administrative authority as well as Head of the department of Obstetrics \& Gynaecology department of Choithram Hospital \& Research Centre, Indore and by taking an informed consent from the postnatal mothers after explaining the importance and purpose of the study. Confidentiality was assured to all samples to get their co - operation. Data collection procedure was carried out same as that of pilot study. The samples were divided into control group and experimental group by envelope method.

Pre assessment:

In this study, experimental group and control group were selected by simple random sampling technique i.e envelope method. All postnatal mothers with episiotomy wound and three days postpartum hospital stay were taken. Procedure was explained and informed consent was taken. Socio demographic data (age in years, education, occupation, residence and family income) and obstetrical data (parity, history of present medical illness, indications and type of delivery) were collected. Pre intervention score of the episiotomy wound was assessed by REEDA wound healing assessment scale in both the groups. Average time taken was tem minutes.

Intervention:

In experimental group, the pre interventional score was assessed by the REEDA wound healing assessment scale on the first day before giving the intervention. The researcher then cleaned the vulva and the episiotomy wound with distilled water and applied chlorhexidine on the episiotomy wound and exposed it to infra red rays for ten minutes. This was done twice a day (morning and evening) for three days. Average time taken was fifteen minutes.

In control group, the pre interventional score was assessed by the REEDA wound healing assessment scale on the first day before giving the routine care. The researcher then gave the routine care to the sample (cleaning the vulva and episiotomy wound with distilled water and application of betadine or nadoxin and exposed it to infra red rays for ten minutes). This was done twice a day (morning and evening) for three days. Average time taken was fifiteen minutes.

Post assessment:

On the third day after giving intervention in experimental group and routine care in the control group (evening), post interventional score was assessed in both the groups. REEDA score was analysed by subtracting the post interventional score from the pre interventional score

\section{RESULTS}

Section I: Socio Demographic Variables Of The Postnatal Mothers

Control group: Data presented table no. 1 (a) shows that out of 20 samples more than half of the samples $13(65 \%)$ were in 26-30 age group, $4(20 \%)$ belonged to $31-35$ years, $2(10 \%)$ belonged to $21-25$ years and only $1(5 \%)$ belonged to $<20$ years. Regarding educational status of postnatal mothers, $16(80 \%)$ of the samples were graduates, $4(20 \%)$ were postgraduates and none of the samples belonged to secondary or higher secondary group. Data presented in table 1 (b) shows that majority $11(55 \%)$ of the samples were housewives, $6(30 \%)$ had their own business, $3(15 \%)$ were in service and none of them were labourers.

Regarding the residence majority 17 (85\%) of the samples belonged to urban and $3(15 \%)$ belonged to rural.

Majority $9(45 \%)$ of the samples have $41,000-50,000$ as family income, $8(40 \%)$ have $>50,000,3(15 \%)$ have 31,000 40,000 and none of the samples have 20,000-30,000.

Experimental group: Data presented in table no. 1 (a) reveals that out of 19 postnatal mothers $11(57.9 \%)$ were in the age group 26-30, $6(31.6 \%)$ belonged to $21-25$ years, $2(10.5 \%)$ belonged to 31-35 years and none of the postnatal mothers belonged to $<20$ years. With regard to education majority 16 $(84.2 \%)$ were graduates, $3(15.8 \%)$ were postgraduates and none of them belonged to secondary or higher secondary.

Data presented in table no 1 (b) reveals that out of 19 postnatal mothers $10(52.6 \%)$ were housewives, $7(36.8 \%)$ had their own business, $2(10.5 \%)$ were in service and none of the postnatal mothers were labourers.

Majority $17(89.5 \%)$ resided in urban area whereas only 2 $(10.5 \%)$ postnatal mothers resided in rural area.

More than half of the samples $11(57.9 \%)$ had 41,000 50,000 as their family income, $7(36.8 \%)$ had $>50,000$ family income, only $1(5.3 \%)$ sample had 31,000-40,000 family income and none of the samples had 20,000 - 30,000 family income. 


\section{Section II: Obstetrical Data Of The Postnatal Mothers}

Table 1: Frequency and Percentage distribution of obstetrical data of postnatal mothers

$(\mathrm{N}=20+19=39)$

\begin{tabular}{|c|c|c|c|c|c|}
\hline \multirow{2}{*}{$\begin{array}{l}\text { S. } \\
\text { No. }\end{array}$} & \multirow[t]{2}{*}{ Variable } & \multicolumn{2}{|c|}{ Control group } & \multicolumn{2}{|c|}{ Experimental group } \\
\hline & & f & $\%$ & f & $\%$ \\
\hline \multirow[t]{3}{*}{01.} & Parity & & & & \\
\hline & Primigravida & 06 & 30 & 16 & 84.2 \\
\hline & Multigravida & 14 & 70 & 03 & 15.8 \\
\hline \multirow[t]{6}{*}{02.} & $\begin{array}{l}\text { History of present medical } \\
\text { illness }\end{array}$ & & & & \\
\hline & Anemia & 01 & 05 & 0 & 0 \\
\hline & Oligohydraminos & 03 & 15 & 03 & 15.8 \\
\hline & Diabetes mellitus & 0 & 0 & 0 & 0 \\
\hline & PIH & 01 & 05 & 02 & 10.5 \\
\hline & None & 15 & 75 & 14 & 73.7 \\
\hline \multirow[t]{3}{*}{03.} & Indications of episioto my & & & & \\
\hline & Rigid perineum & 09 & 45 & 11 & 57.9 \\
\hline & Any other & 11 & 55 & 08 & 42.1 \\
\hline \multirow[t]{5}{*}{04.} & Type of de livery & & & & \\
\hline & Spontaneous & 18 & 90 & 16 & 84.2 \\
\hline & delivery & & & & \\
\hline & Augmented & 02 & 10 & 03 & 15.8 \\
\hline & delivery & & & & \\
\hline
\end{tabular}

Control group

Data presented in table 1 shows that nearly three fourth $14(70 \%)$ of the postnatal mothers were multigravida and 6 $(30 \%)$ were primigravida.Three fourth of the samples $15(75 \%)$ had no present medical illness, $3(15 \%)$ had oligohydraminos, $1(5 \%)$ had anemia, $1(5 \%)$ had PIH and none of the postnatal mothers had diabetes mellitus. It reveals that indications for episiotomy in control group were big baby $2(18 \%)$, twins 2 $(18 \%)$, ventouse delivery $2(18 \%)$, previous perineal surgery 3 $(27.27 \%)$, breech $2(18 \%)$ and $9(45 \%)$ had rigid perineum. Regarding type of delivery, majority $18(90 \%)$ had spontaneous delivery and only $2(10 \%)$ had augmented delivery.

Experimental group

Data presented in table no 1 reveals that majority 16 $(84.2 \%)$ of the postnatal mothers were primigravid and only 3 (15.8\%) were multigravida.More than half of the postnatal mothers $14(73.7 \%)$ had no history of present medical illness, 3 (15.8\%) and $2(10.5 \%)$ had oligohydraminos PIH respectively whereas none of the samples had Diabetes Mellitus or anemia. It reveals that majority $11(57.9 \%)$ had rigid perineum while 8 $(42.1 \%)$ of the postnatal mothers had other reasons as ventouse delivery $3(15.78 \%)$, twins $2(10.52 \%)$, breech $2(10.52 \%)$, previous perineal surgery $1(5.28 \%)$ and none of the postnatal mothers had big baby. Most of the patients had spontaneous delivery $16(84.2 \%)$ while the remaining $3(15.8 \%)$ postnatal mothers had augmented delivery

Section III: Level Of Healing Of Episiotomy Wound Among Postnatal Mothers In Controlgroup And Experimental Group

Experimental Group: Data presented in fig. 1 depicts that out of 19 postnatal mothers' majority $18(94.73 \%)$ had their episiotomy wound as completely healed, only $1(5.27 \%)$ postnatal mother had her episiotomy wound as partially healed and none of the samples belonged to not healed category.

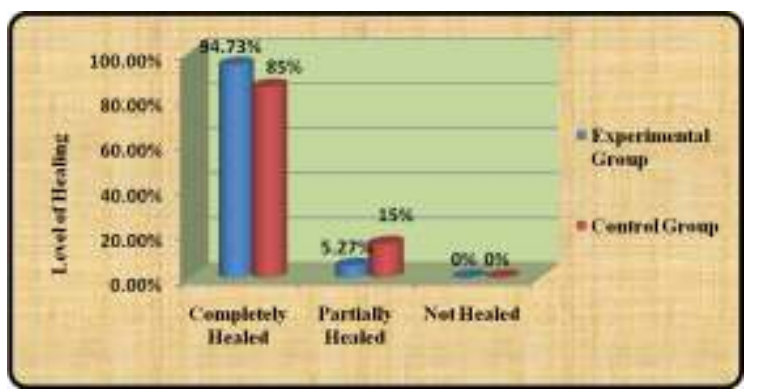

Figure 1: Cylindrical diagram showing level of healing of samples among control group and experimental group

TABLE No. 2 Mean, mean difference, standard deviation, standard error, d.f., \& $t$ value between post test scores of control group \& experimental group p $<0.05^{*} \mathrm{p}<0.01^{* *}$ p $<0.001 * * *$ S - Significant

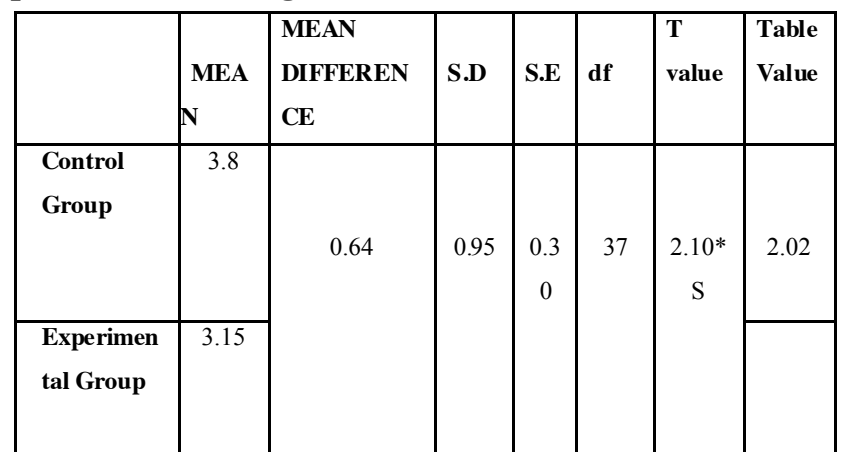

TABLE No. 3 Mean, mean difference, standard deviation, standard error, d.f. \& $t$ value between pre test and post test scores of REEDA in experimental group $\mathrm{p}<0.05^{*} \mathrm{p}<$ $0.01 * * \quad \mathbf{p}<0.001 * * * \mathrm{~S}-$ Significant

\begin{tabular}{|l|l|l|c|c|c|c|c|}
\hline & $\begin{array}{l}\text { ME } \\
\text { AN }\end{array}$ & $\begin{array}{l}\text { ME AN } \\
\text { DIFFE RE } \\
\text { NCE }\end{array}$ & S.D & S.E & df & $\begin{array}{l}\text { T } \\
\text { value }\end{array}$ & $\begin{array}{c}\text { Table } \\
\text { Value }\end{array}$ \\
\cline { 1 - 6 } $\begin{array}{l}\text { Pre test } \\
\text { Score }\end{array}$ & 5.47 & 2.31 & 0.8 & 0.2 & 18 & 11.40 & 3.92 \\
\cline { 1 - 2 } $\begin{array}{l}\text { Post test } \\
\text { Score }\end{array}$ & 3.16 & & 8 & 0 & & $\begin{array}{c}* * * \\
\text { S }\end{array}$ & \\
\hline
\end{tabular}

Control Group: Data presented in fig. 1 reveals that majority 17 $(85 \%)$ of the postnatal mothers had their episiotomy wound as completely healed, $3(15 \%)$ out of 20 postnatal mothers had their episiotomy wound as partially healed and none of the samples had their episiotomy wound as not healed

Data presented in table no. 2 shows that the computed $t$ value 2.10 at $\mathrm{df} 37$ with S.D. 0.95 indicates that there was a significant difference in post test healing level at the level $p<0.05$ which shows there was a significant difference of healing of episiotomy wound on third day among postnatal mothers in control group and experimental group. Hence H1 is accepted.

Data presented in table 3 shows that the computed $t$ value 18.76 at $\mathrm{df} 18$ with S.D. 0.88 indicates that there was a significant difference in post test healing level of the postnatal mothers at the level $p<0.05$ which shows there was a significant difference in the healing of episiotomy wound by the application of chlorhexidine among postnatal mothers in experimental group. Hence $\mathrm{H} 2$ is accepted. 


\section{DISCUSSION}

1.Assessment Related To The Level Of Healing Of Episiotomy Wound Among Postnatal Mothers

Findings of the study related to assessment of the level of healing of episiotomy wound among postnatal mothers in experimental group shows that majority $18(94.73 \%)$ of the samples had their episiotomy wound as completely healed. 1 $(5.27 \%)$ sample out of 19 samples had her episiotomy wound as partially healed and none of the samples were observed as not healed.

In control group, three fourth of the samples 17 (85\%) had their episiotomy wound as completely healed, $3(15 \%)$ out of 20 samples had their episiotomy wound as partially healed and none of the samples had their wound as not healed.

Usually episiotomy wound gets completely healed in few days to few weeks. In the present study, the process of wound healing is observed on the third day.

The above findings are supported by:

Ragbih O D et al (2010) 6 An experimental study was conducted to compare chlorhexidine-alcohol versus povidone iodine for surgical site asepsis.849 subjects were selected randomly.409 were preoperatively cleansed with chlorhexidine alcohol whereas 440 were cleansed with povidone iodine. Presence of infection was assessed after 30 days. The overall rate of infection was significantly lower in chlorhexidine alcohol group than povidone iodine group $(9.5 \% \mathrm{v} / \mathrm{s} 16.1 \%, \mathrm{p}<0.04$; relative risk $0.59,95 \%$ confidence interval, 0.41 to 0.85 ). Chlorhexidine alcohol was significantly more protective than povidone iodine against both superficial incision infections $(4.2 \%$ vs $8.6 \%, p=0.008)$ and deep incisional infection $(1 \%$ vs $3 \%, \mathrm{p}=0.05)$ but not against organ space infection $(4.4 \%$ vs $4.5 \%$ ). Study concluded that preoperative cleansing of patient's skin with chlorhexidine-alcohol is superior to cleansing with povidone iodine for preventing surgical site infection after surgery.

2.Effectiveness Of Healing Of Episiotomy Wound Among Postnatal Mothers In Control Group And Experimental Group

H1: There is significant difference in episiotomy wound healing status among control group and experimental group at the level of $\mathrm{p} \leqslant 0.05$.

Data presented in table no. 04 shows that the computed $t$ value 2.106 at df 37 with S.D. 0.954 indicates that there was a significant difference in post test healing level at the level $p<$ 0.05 which shows there was a significant difference of healing of episiotomy wound among postnatal mothers in control group and experimental group. Hence, $\mathrm{H} 1$ is accepted.

The findings were supported by the following study:

Manjula et al (2011) 7 A experimental study was conducted to assess the effectiveness of honey versus betadine on episiotomy wound healing. Sample size was 60 postnatal mothers ( 30 honey and 30 betadine). Findings revealed that in the honey group on day 1 the episiotomy wound assessment score mean was 8.03 , on day 5 mean score reduced to 0.27 . In betadine gropu day 1 mean score was 8.23 and on day 5 mean score was 1.4. There was a mean difference of 7.8 in honey group and 6.83 in betadine group. The obtained t value on day 2 (3.818), day 3 (2.967), day 4 (4.2) and day 5 (4.02) found to be significant $(\mathrm{p}<$
0.05 ) at 0.01 and 0.05 level of significance. This reveals that as the day progresses episiotomy wound healing was good in both thegroups but it was faster in honey group than in betadine group. Study results denoted that application of honey has significant influence on episiotomy wound healing.

3.Effectiveness Of Chlorhexidine Among Postnatal Mothers In Experimental Group

$\mathrm{H} 2$ : There is significant difference in episiotomy wound healing status in experimental group after the application of chlorhexidine at the level of $\mathrm{p} \leqslant 0.05$.

Data presented in table 05 shows that the computed $t$ value 18.76 at df 18 with S.D. 0.88 indicates that there was a significant difference in post test healing level of the postnatal mothers at the level $\mathrm{p}<0.05$ which shows there was a significant difference in the healing of episiotomy wound by the application of chlorhexidine among postnatal mothers in experimental group. (Refer Fig No. P No. )

The above findings were supported by the following study:

RicaRdo $M$ et al (2005) 8 conducted a randomized controlled trial comparing the efficacy, acceptability and safety of chlorhexidine digluconate against povidone iodine and lactic acid as an external genital antiseptic in women who have undergone vaginal surgery. A total of 270 women from June 17, 2005 until July 27, 2005 at the Philippine General Hospital, were randomly assigned to use Chlorhexidine Digluconate, Povidone-Iodine or Lactic Acid as antiseptic genital wash during and after the surgical procedure. All participants were asked to come back 1, 2, 4 and 6 weeks after discharge. Assessment was done comparing the efficacy, acceptability and safety of the three antiseptic solutions in preventing surgical site infection. The results of the study show that chlorhexidine digluconate when used as a preoperative and postoperative external genital wash by women who underwent vaginal surgery is associated with the least number of surgical site infection compared to povidone-iodine and lactic acid. Only 1 out of 71 observed participants using chlorhexidine digluconate (1.4\%, 95\% CI: .04 - 7.6\%) developed a surgical site infection, whereas 2 out of 71 observed participants using povidine-iodine developed a surgical site infection $(2.8 \%, 95 \%$ CI: $0.34-9.8 \%)$ and 5 out of the 74 observed participants using lactic acid developed a surgical site infection $(6.8 \%, 95 \%$ CI: $2.2-15.1)$. The antiseptic effect of chlorhexidine digluconate appeared superior over povidone-iodine and lactic acid in preventing surgical site infection when used as a genital wash.

\section{Benefits OfChlorhexidine Over Prevailing Practices}

Chlorhexidine is available as diacetate, gluconate and dihydrochloride; the gluconate is most frequently used in wound management. Chlorhexidine when applied to skin or mucous membranes binds to the tissues and has a persistent and residual anti-infective activity. It binds to the cell wall of bacteria and disrupts the cytoplasmic membrane eventually causing cell death. It has few to no side effects. It is to an easy, inexpensive, and accessible alternative to the standard approach.

Chlorhexidine is also cost effective as the rate of betadine is Rs. 81 per 15 gm; nadoxin is Rs. 64 per $10 \mathrm{gm}$ whereas chlorhexidine is Rs. 29.50 per $15 \mathrm{gm}$.

\section{CONCLUSION}

The crux of the study finding lay open that the application of chlorhexidine on episiotomy wound promotes in wound 
healing as it helps in early granulation when applied to skin or mucous membranes. It binds to the tissues and has a persistent and residual anti-infective activity. It has few to no side effects. It is to an easy, inexpensive, and accessible alternative to the standard approach.

\section{REFERENCES}

1. Fraser MD, Cooper A M. Myles Textbook for Midwives. 14th ed. Churchill Livingstone. 2000

2. Robinson J.N., Norwitzer E.R., Cohen A.P., Lieberman E. Predictors of episiotomy use at first spontaneous vaginal delivery. Obstet Gynecol. 2000: 96-214.

3. Gupta J.K., Hofmer G.J., Shehnmar M. Position in second stage of labour for women without epidural anesthesia.
Cochrane Database Syst. Rev 2012: 5:CD002006.

4. Janet A, Patricia, Prake. Maternal and Newborn Health. 1st ed. Canada. Jones and Bartllet Publishers: 2007. 168

5. Ragbih O D, Mathew J Wall etal. Povidone iodine-adverse effects. NEngl J Med 2010 Jan 7:362(1):18-26.

6. Manjula P. Effectiveness of honey versus betadine on episiotomy wound healing. I-manager's journal of nursing. 2011 Feb- Apr. [cited on 2013 May 5]: 2(1): 32-37. Available from: http://www.deepdyve.com/lp/i-managerpublications/effectiveness-of-honey-versus-betadine-onepisiotomy-wound-healing-M2d2BIyUIs/2

7. RicaRdo M., Manalastas JR, Elizabeth Isiol et al. J Obs and Gynaecol. 2007:31(3):121 